\title{
Editorial
}

\section{Looking back, looking forward}

Asian Business \& Management (2015) 14, 1-3. doi:10.1057/abm.2014.19

I hope 2015 has started well for you all. I am delighted to present this first issue in the 14th volume of Asian Business \& Management $(A B M)$. As has become customary at $A B M$, I would like to take this opportunity to present a brief summary of developments in the past year and plans for the future.

\section{Positioning}

Looking forward, the overall vision of the journal will remain unchanged from that laid out in my 2012 and 2014 editorials (Witt, 2014, p. 2):

$A B M$ is, as the name suggests, a journal on business and management in Asia. It views itself as an academic general management and business journal, that is, we are in principle open to all disciplines and fields of research on management and business - subject, of course, to the condition that submissions must be related to Asia. We especially encourage papers that draw on one of the various streams of the business systems literature, broadly conceived, to generate new insights into the societal embeddedness of firms in Asia and the consequences of such embeddedness on managerial and business processes, structures, and outcomes.

Likewise, all suggestions and guidelines laid out in the previous editorials remain relevant, and it is my hope that they will help authors hoping to publish in $A B M$ to maximize their chances of success.

\section{Editorial Board}

The past year has seen the widened implementation of our new editorial structure. Peter Dowling (La Trobe Business School), Martin Hemmert (Korea University) and Dylan Sutherland (Durham University) joined as new Associate Editors, bringing with them, respectively, extensive experience and expertise in human resource management, innovation as well as Japanese and Korean business, and outward foreign direct investment from emerging markets, especially China. As Editor in 
Chief, I am delighted to have them on board. I am also deeply grateful for the continued dedication and contribution in their roles as Associate Editors from Asli Colpan, Axele Giroud, Nahee Kang, Leonard Lynn and Carlos Noronha.

In the months ahead, we will start to implement further structural changes. In particular, our existing 'Editorial Board' will be renamed as 'Editorial Review Board', and we will work to ensure continued alignment between the board and the journal's mission. I will provide updates as this work proceeds.

\section{Numbers of Papers}

As regular readers will have noticed, the last few issues in 2014 were rather slimmer than usual. This is the result of tighter quality standards in the review process, and we all at $A B M$ expect this to be a temporary phenomenon. Palgrave and I have been actively working on increasing awareness of $A B M$ among a wider audience. Paired with likely improvements in impact factors and rankings and other initiatives, laid out below, this should allow us to see a strengthening pipeline over time.

\section{Perspective Papers}

One such initiative sees its debut in this issue: We expect to be running, on an irregular basis, perspective papers by leading scholars that are intended to help open up new avenues for research. Suggestions for such perspective papers are more than welcome.

Tetsuo Abo's article in this issue inaugurates this new series. It summarizes decades of research on 'hybrid factories' - that is, the adaptation of Japanese manufacturing to local conditions in host countries. These findings have so far not been disseminated widely outside Japan, and they are highly relevant to a range of international business research areas. To help build a bridge with business and management research, two commentaries, by Axele Giroud as well as by Roger Strange and Norifumi Kawai, provide interpretations of the relevance of Prof. Abo's findings for current debates in these fields. My hope is that jointly, these pieces will prove foundational for future research, and I thank all the authors for their willingness to contribute to this experiment.

\section{Special Issues}

A second initiative concerns special issues. As long-time readers will know, $A B M$ has a strong tradition of special issues on important topics in business and management. Some of these special issues grow out of the conferences of the associations 
supporting $A B M$, and we will continue with this custom. We will also continue to publish special issues around given topic areas - for example, CSR, or Asian varieties of capitalism - but with a new process. The plan is to publish one or, exceptionally, two such special issues per year based on an open competition. We will soon issue an open call for proposals for special issues, and I intend to institutionalize this as an annual process. I hope to see these special issues, which will follow the same standards in terms of scholarly rigour as regular papers, become kernels around which future research can grow.

From all of us at $A B M$, I wish you a happy and successful 2015. Stay tuned for further announcements during this year, and as always, any input from you, our readers, is more than welcome.

\section{Reference}

Witt, M.A. (2014) The road ahead. Asian Business \& Management 13(1): 1-4.

Michael A. Witt INSEAD, Editor in Chief. E-mail: abm.editor@insead.edu 